\title{
Spectrometric Methods Used to Determine Heavy Metals and Total Cyanides in Accidental Polluted Soils
}

\author{
A. Mihaly-Cozmuta, L. Mihaly Cozmuta, V. Viman, Gh. Vatca and C. Varga \\ Chemical Department of North University of Baia Mare, Victoriei Str. 76 \\ Baia Mare, Maramures, 4800, Romania
}

\begin{abstract}
The study presents the level of soil pollution in the area adjacent to three sedimentation ponds as a result of an environmental accident. Soil samples from various sites have been collected and analyzed to determine the concentration of heavy metals $(\mathrm{Cu}, \mathrm{Pb}, \mathrm{Zn})$ and total cyanides. The analysis methods used were ICP-AES for heavy metals and the colorimetric for total cyanides. The accuracy of both methods is determined subject to the reproducibility of the results. The values of determined concentrations indicate a deep pollution of the local ecosystem.
\end{abstract}

Key words: ICP-AES, Heavy Metals Pollution, Cyanide Pollution, Colorimetric Method, Sedimentation Ponds

\section{INTRODUCTION}

The contemporary environmental crisis with it unwanted component, the pollution, has a dramatic influence on the environment. To develop and apply strategies to reduce the already existing pollution one must know who the pollutants are, how they depend one each other and what toxic effects they have on the water, soil, air and living organisms, what the level of pollution is.

This article is a study of pollution in the Baia Mare area, one of the most polluted areas in Europe. The increasingly high interest of the scientific community in this area results from its characteristics.

Baia Mare region is located in the NW side of Romania and has a population of about 250,000 people, of which 25,000 work in the mining field. The pollution of the area is characterized by richness and variety: sulphur oxides, aerosols and sedimentary powders with high $\mathrm{Pb}$, $\mathrm{Zn}, \mathrm{Cd}, \mathrm{Mn}$ and $\mathrm{Cu}$ content. High concentrations of chemical pollutants in the area leave their mark upon the health of the ecosystem. Thus, vegetation is not very varied, the number of plants growing in the area being small. The plants do not grow in height, are exfoliated and their leaves present necrosis. The town Baia Mare also presents a series of "unwanted performances" [1]:

* Is the locality with the highest frequency of precipitation in country (many times acid) because of the particle in suspension, which represent nuclei of condensation of water vapours;

* 50,000 t of polluting substances are annually discharged in the Sasar River which crosses the town;
* The rickets and D2 vitamin deficiency are 80\% higher than in the unpolluted towns, the hypertensive diseases by $51 \%$, the metabolic disease and anemia by $50 \%$, dental decay by $48 \%$, cardio-vascular and malign diseases by $300 \%$; the life hope of the citizen is $10-12$ years smaller comparing with the medium age considered 65 .

It is hard to determine when the confrontation with the pollution started as where it concerns this region we may talk about both "historic pollution" and "contemporary pollution".

The historic pollution is caused by the geological structure of the area and the beginning of mining activities since 1932[1].

The contemporary pollution is a consequence of the activities of the mines surrounding and chemical plants in the area which process non-ferrous ores.

The wastewaters from the pollution sources are discharged in two sedimentation ponds (Fig. 1) located at the town outskirts close to five villages.

Remin Sedimentation Pond (so called "the old pond") receives acid wastewaters discharged from three chemical plants of Baia Mare. Built back in 1977, it covers $1,050,000 \mathrm{~m}^{2}$, is $30 \mathrm{~m}$ deep (190 survey mark) and the embankment is $18-20^{\circ}$. The built-up rate of 2 $\mathrm{m} /$ annum has allowed $150,000,000 \mathrm{~m}^{3}$ of tailings to accumulate in the pond. The fact that clay layer on which the pond is built is permeable indicates that the water stored in the pond could penetrate it.

Transgold Sedimentation Pond (called "the new pond") was built in 1993 and collects residual water with a high content of cyanide from the TRANSGOLD Company which treats gold tailing by cyanidation to extract gold and silver. It is about $3.8 \mathrm{~km}$ long and 
covers $70,000 \mathrm{~m}^{2}$. Due to construction problems and the increased amount of rain recorded over December 1999-January 2000, the pond wall collapsed and over $100,000 \mathrm{~m}^{3}$ of cyanide-water were spilled and dispersed in adjacent rivers[2] . After the accident a channel about $4 \mathrm{~m}$ wide all around the pond and a protection area on the NW side was built with the purpose of collecting the wastewaters accidentally discharged.

Apart from the operational sedimentation ponds, there is third one (Fig. 1) in the area that has been in preservation about 20 years. The area where the wastewater used to be discharge was covered in soil and "rehabilitated" by planting bushes.

The strong winds in the sedimentation ponds area blow fine particles of their walls, which are carried and deposited on the adjacent area thus contaminating the air, soil and vegetation. Also, the infiltration of water from ponds charged with a high heavy metal and cyanide content has a major contribution to the dispersion of pollutants in soil and groundwater. Considering the above-presented aspects becomes obvious the danger presents by this area on the environment.

\section{MATERIALS AND METHODS}

The purposes of this paper is to study both the level of heavy metal and cyanide pollution of the soil in the protection area of Transgold Sedimentation Pond and the accuracy of the methods of analysis employed.

To this end, $24^{\text {th }}$ soil samples have been collected from 12 sampling sites located about $200 \mathrm{~m}$ from each other (Fig. 1), which were precisely positioned using a GPS 310 Magellan device.

Two samples have been collected from each site, one from the soil surface $(5 \mathrm{~cm})$ after removing of vegetation layer and the other in depth $(30 \mathrm{~cm})$ each of them weighing about $1 \mathrm{Kg}$. The samples were stored in plastic bags that were then marked and prepared for analysis. They were air-dried at room temperature prior to grinding in agate mortars, sieving (at-500 microns) and dissolved.

The samples designates for heavy metals analysis were processed as follows ${ }^{3}$ : $10 \mathrm{ml}$ of $1: 1(\mathrm{v} / \mathrm{v}) \mathrm{HCl}$ was added to $0.2 \mathrm{~g}$ of air-dried soil in a $150 \mathrm{ml}$ beaker and the sample heated to near dryness. After cooling, $10 \mathrm{ml}$ of $3: 1(\mathrm{v} / \mathrm{v}) \mathrm{HNO}_{3}+\mathrm{HCl}$ Lunge mixture, was added and again the acid was evaporated to near dryness. The residue was dissolved in $25 \mathrm{ml} \mathrm{HCl} \mathrm{1:4} \mathrm{(v/v)} \mathrm{and} \mathrm{heated}$ for approximately 15 minutes in open air. The sample was then transferred into a $100 \mathrm{ml}$ volumetric flask and diluted to volume with distilled water. The sample was filtered to remove suspended particulate matter before analysis. The heavy metals contents were determined using ICP-AES method [4,5], at specific wave lengths for each metal: $283.3 \mathrm{~nm}$ for $\mathrm{Pb}, 324.7 \mathrm{~nm}$ for $\mathrm{Cu}$ and $213.9 \mathrm{~nm}$. for $\mathrm{Zn}$. The concentrations of heavy metals in soil samples, $\mathrm{C}$, were calculated as follow:
$\mathrm{C}=\mathrm{C}_{\mathrm{o}} \cdot \mathrm{V} / \mathrm{m}$

where:

C- the concentration of heavy metal in soil sample, $\mathrm{mg} / \mathrm{kg}$

$\mathrm{C}_{0^{-}}$the metal concentration read from calibration curve, $\mathrm{mg} / \mathrm{l}$

$\mathrm{V}$ - the total volume of solution, $\mathrm{ml}$

$\mathrm{m}$ - the weight of dried sample taken for analysis, $g$

Total cyanides were determined using colorimetric method [3]. It is based on conversion of $\mathrm{CN}^{-}$to $\mathrm{CNCl}$ by reaction with chloramines- $\mathrm{T}$ at $\mathrm{pH}<8$ and formation of red-blue dye on addition of a pyridine-barbituric acid reagent. The absorbance of the solution was measured at $578 \mathrm{~nm}$. The concentrations of total cyanide in soil samples were calculated using the equation:

$\operatorname{mg~} \mathrm{CN}^{-} / 1=(\mathrm{A} \cdot \mathrm{B}) /(\mathrm{C} \cdot \mathrm{D})$

where:

A- $\quad \mu \mathrm{g} \mathrm{CN}-$ read from calibration curve $(50 \mathrm{ml}$ final volume)

B- total volume of absorbing solution from the distillation, $\mathrm{ml}$

C- volume of original sample used in the distillation, $\mathrm{ml}$

D- volume of absorbing solution used in colorimetric test, $\mathrm{ml}$

\section{RESULTS AND DISCUSSION}

By comparing the values of the copper concentrations (Fig. 2) in the analyzed samples with those from the Romanian Standards presented in the Table 1[6] may notice that the copper normal value of concentration is exceeded in almost all the cases. There are two exceptions, samples 6 and 8 where the concentrations of $\mathrm{Cu}$ are lower than $0.35 \mathrm{mg} / \mathrm{kg}$ detection limit of the ICP-AES method. Concerning of alert and intervention levels the $\mathrm{Cu}$ concentrations in soil samples are higher except the samples 6, 7 and 8. In the most copper concentrated sample (3 at $30 \mathrm{~cm}$ depth) the concentration of $\mathrm{Cu}(1,183 \mathrm{mg} / \mathrm{kg})$ is 2.36 times higher than the intervention level $(500 \mathrm{mg} / \mathrm{kg})$.

In case of $\mathrm{Pb}$ there are not samples less concentrated than normal values (Fig. 3) and all the samples are higher than the alert level. Only two samples, 6 (surface) and 8 (surface and depth), have $\mathrm{Pb}$ concentrations under intervention level. The maximum concentration of $6,214 \mathrm{mg} / \mathrm{kg} \mathrm{Pb}$ in soil (sample 12 at $30 \mathrm{~cm}$ depth) is higher 6.214 times than the 1,000 $\mathrm{mg} / \mathrm{kg}$ intervention level (less sensitive).

All the soil samples have $\mathrm{Zn}$ concentrations over the normal values (Fig. 4), samples 6, 7 and 8 both surface and depth exceeds alert level and the same samples are under the intervention level. 
Table 1: Romanian Standards for Heavy Metals and Total Cyanides Concentrations in Soil

\begin{tabular}{llllll}
\hline Element & Normal values & \multicolumn{2}{l}{ Alert level $\mathrm{mg} / \mathrm{kg}$} & \multicolumn{2}{c}{ Intervention level $\mathrm{mg} / \mathrm{kg}$} \\
& $\mathrm{mg} / \mathrm{kg}$ & sensitive & less sensitive & sensitive & less sensitive \\
\hline $\mathrm{Cu}$ & 20 & 100 & 250 & 200 & 500 \\
$\mathrm{~Pb}$ & 20 & 50 & 250 & 100 & 1,000 \\
$\mathrm{Zn}$ & 100 & 300 & 700 & 600 & 1,500 \\
$\mathrm{CN}^{-}$(Total) & $<5$ & 100 & 200 & 250 & 500 \\
\hline
\end{tabular}

Table 2: Calculation of Reproducibility of the ICP-AES Method' Results

\begin{tabular}{|c|c|c|c|c|c|c|c|}
\hline $\begin{array}{l}\text { Number of } \\
\text { sample }\end{array}$ & Element & $\begin{array}{l}\text { Results } \\
\mathrm{mg} / \mathrm{kg}\end{array}$ & $\begin{array}{l}\text { Mean } \\
\text { value }\end{array}$ & $\begin{array}{l}\text { Sample } \\
\text { standard } \\
\text { deviation, } \mathrm{s}\end{array}$ & $\begin{array}{l}\text { Population } \\
\text { standard } \\
\text { deviation, S }\end{array}$ & $\begin{array}{l}\text { Relative } \\
\text { standard } \\
\text { deviation } \\
\text { RSD, \% }\end{array}$ & $\begin{array}{l}\text { Result } \\
\mathrm{mg} / \mathrm{kg}\end{array}$ \\
\hline \multirow[t]{3}{*}{$\begin{array}{l}7 \text { at } 30 \mathrm{~cm} \\
\text { depth }\end{array}$} & $\mathrm{Cu}$ & $\begin{array}{l}33 \\
27\end{array}$ & 30 & 4.2 & 2.98 & 10 & $30 \pm 3$ \\
\hline & $\mathrm{Pb}$ & $\begin{array}{l}209 \\
210\end{array}$ & 209.5 & 2.2 & 1.6 & 1 & $210 \pm 2$ \\
\hline & $\mathrm{Zn}$ & $\begin{array}{l}180 \\
246\end{array}$ & 213 & 46.7 & 33.1 & 16 & $213 \pm 34$ \\
\hline
\end{tabular}

Table 3: Calculation of the Reproducibility of the Colorimetric Method's Results

\begin{tabular}{llllllll}
\hline $\begin{array}{l}\text { Number } \\
\text { of sample }\end{array}$ & Element & $\begin{array}{l}\text { Results } \\
\mathrm{mg} / \mathrm{kg}\end{array}$ & $\begin{array}{l}\text { Mean } \\
\text { value }\end{array}$ & $\begin{array}{l}\text { Sample } \\
\text { standard } \\
\text { deviation, } \mathrm{s}\end{array}$ & $\begin{array}{l}\text { Population } \\
\text { standard } \\
\text { deviation } \\
\text { S }\end{array}$ & $\begin{array}{l}\text { Relative } \\
\text { standard } \\
\text { deviation } \\
\text { RSD, \% }\end{array}$ & $\begin{array}{l}\text { Result } \\
\mathrm{mg} / \mathrm{kg}\end{array}$ \\
\hline $\begin{array}{l}1 \text { at } \\
\text { surface } \\
8 \text { at }\end{array}$ & $\mathrm{CN}^{-}$ & $76 ; 75 ; 74$ & 75 & 0.82 & 0.47 & 1.09 & $75 \pm 0.8$ \\
$\begin{array}{l}30 \mathrm{~cm} \\
\text { depth }\end{array}$ & & $9 ; 8 ; 10$ & 9 & 0.99 & 0.57 & 11 & $9 \pm 0.9$ \\
\hline
\end{tabular}

Table 4: Deviation of Experimental Results from Mean Value

\begin{tabular}{llllll}
\hline $\begin{array}{l}\text { Number of } \\
\text { sample }\end{array}$ & Depth & \multicolumn{2}{l}{ Concentration of heavy metals $(\mathrm{mg} / \mathrm{kg})$} & \multicolumn{2}{l}{ Total cyanides } \\
1 & 2 & $\mathrm{Cu}$ & $\mathrm{Pb}$ & $\mathrm{Zn} / \mathrm{kg})$ & 6 \\
\hline 1 & $5 \mathrm{~cm}$ & $347 \pm 1$ & $666 \pm 11$ & $1093 \pm 12$ & $75 \pm 0.8$ \\
& $30 \mathrm{~cm}$ & $386 \pm 4$ & $5788 \pm 13$ & $1016 \pm 5$ & $19 \pm 0.2$ \\
2 & $5 \mathrm{~cm}$ & $214 \pm 2$ & $504 \pm 41$ & $724 \pm 4$ & $4 \pm 0.4$ \\
& $30 \mathrm{~cm}$ & $432 \pm 1$ & $580 \pm 20$ & $922 \pm 8$ & $4 \pm 0.4$ \\
3 & $5 \mathrm{~cm}$ & $895 \pm 2$ & $2309 \pm 20$ & $4351 \pm 45$ & $52 \pm 5$ \\
& $30 \mathrm{~cm}$ & $1183 \pm 1$ & $1836 \pm 25$ & $5393 \pm 16$ & $3 \pm 0.3$ \\
4 & $5 \mathrm{~cm}$ & $986 \pm 3$ & $536 \pm 19$ & $1471 \pm 6$ & $183 \pm 18$ \\
& $30 \mathrm{~cm}$ & $577 \pm 2$ & $998 \pm 16$ & $1120 \pm 11$ & $22 \pm 0.2$ \\
5 & $5 \mathrm{~cm}$ & $969 \pm 3$ & $2087 \pm 21$ & $3128 \pm 10$ & $20 \pm 2$ \\
& $30 \mathrm{~cm}$ & $724 \pm 4$ & $3728 \pm 24$ & $3983 \pm 16$ & $64 \pm 6$ \\
6 & $5 \mathrm{~cm}$ & $<\mathrm{DL}$ & $53 \pm 0.1$ & $184 \pm 12$ & $13 \pm 1$ \\
& $30 \mathrm{~cm}$ & $<\mathrm{DL}$ & $123 \pm 0.5$ & $200 \pm 19$ & $14 \pm 1$ \\
7 & $5 \mathrm{~cm}$ & $19 \pm 0.04$ & $142 \pm 1$ & $168 \pm 1$ & $11 \pm 1$ \\
& $30 \mathrm{~cm}$ & $30 \pm 3$ & $213 \pm 34$ & $210 \pm 2$ & $12 \pm 1$ \\
8 & $5 \mathrm{~cm}$ & $<\mathrm{DL}$ & $88 \pm 1$ & $151 \pm 1$ & $9 \pm 0.9$ \\
& $30 \mathrm{~cm}$ & $<\mathrm{DL}$ & $84 \pm 0.3$ & $149 \pm 3$ & $9 \pm 0.9$ \\
9 & $5 \mathrm{~cm}$ & $362 \pm 3$ & $554 \pm 2$ & $3435 \pm 13$ & $7 \pm 0.7$ \\
10 & $5 \mathrm{~cm}$ & $519 \pm 1$ & $3064 \pm 50$ & $644 \pm 4$ & $11 \pm 0.1$ \\
& $30 \mathrm{~cm}$ & $333 \pm 4$ & $3902 \pm 126$ & $585 \pm 4$ & $12 \pm 1$ \\
11 & $5 \mathrm{~cm}$ & $397 \pm 1$ & $869 \pm 40$ & $1391 \pm 4$ & $54 \pm 5$ \\
& $30 \mathrm{~cm}$ & $604 \pm 2$ & $4260 \pm 36$ & $1155 \pm 3$ & $15 \pm 2$ \\
12 & $5 \mathrm{~cm}$ & $465 \pm 2$ & $5361 \pm 40$ & $1368 \pm 19$ & $1 \pm 0.1$ \\
& $30 \mathrm{~cm}$ & $648 \pm 3$ & $6214 \pm 26$ & $1293 \pm 5$ & $24 \pm 2$ \\
\hline
\end{tabular}




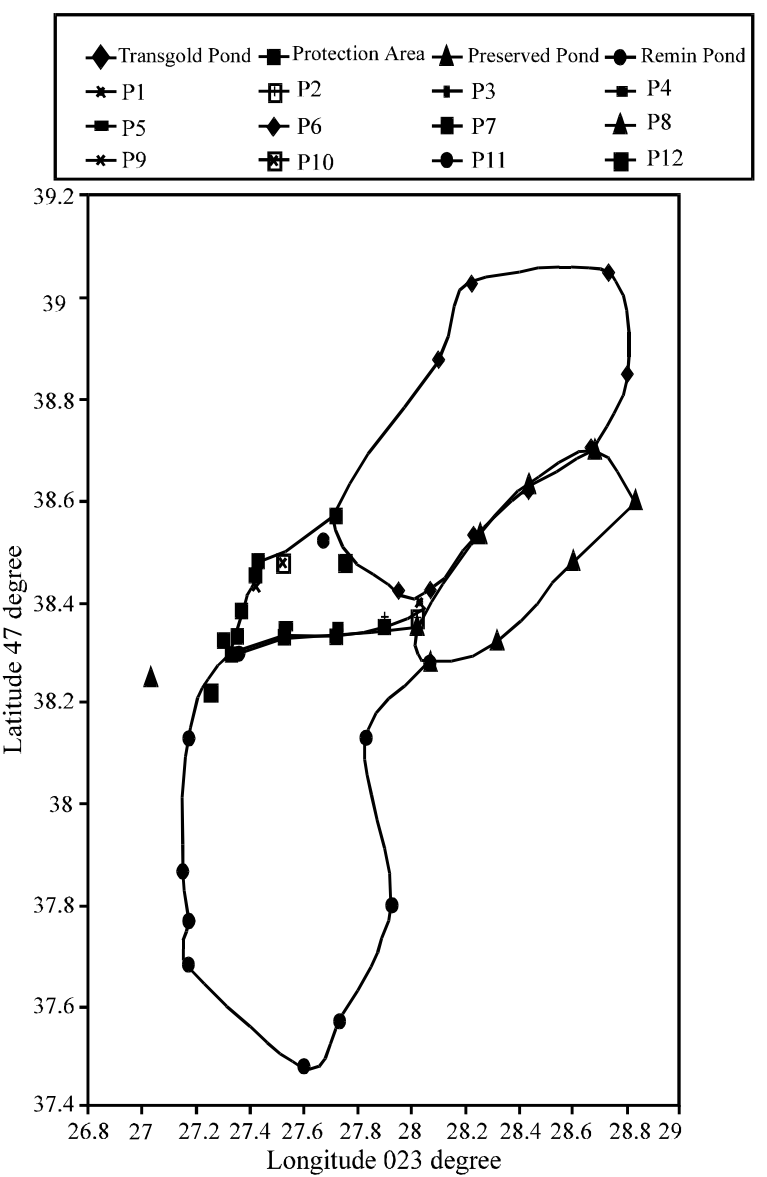

Fig. 1: Sedimentation Ponds Area

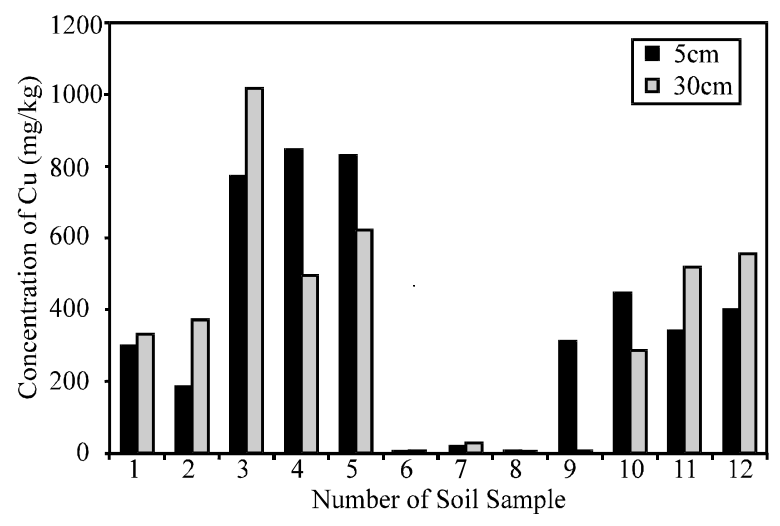

Fig. 2: Concentration of $\mathrm{Cu}$ in Soil Samples

Total cyanides (Fig. 5) are over normal values and mostly under the alert level, except samples 4 at surface.

The higher concentrations of heavy metals than total cyanides can be explained base on cumulative property of heavy metals in soil while cyanides are degraded in time.

The analysis of Figs. 2-4 does not indicate a uniform variation of the heavy metal concentration reported to

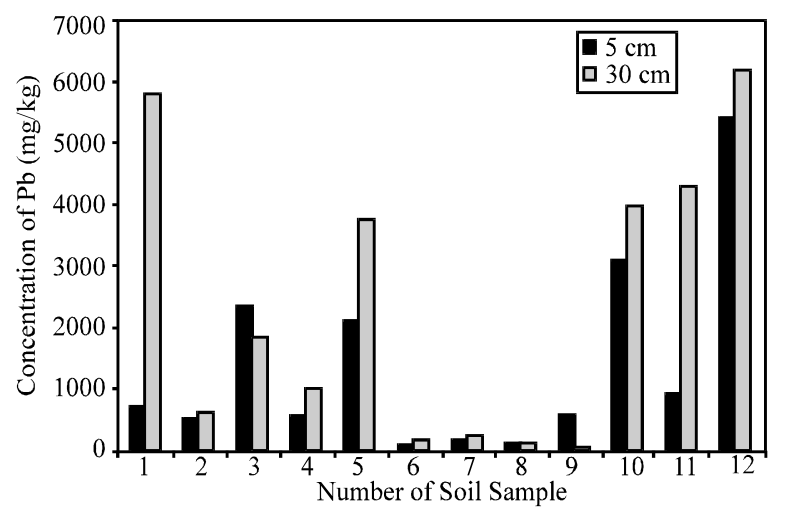

Fig. 3: Concentration of $\mathrm{Pb}$ in Soil Samples

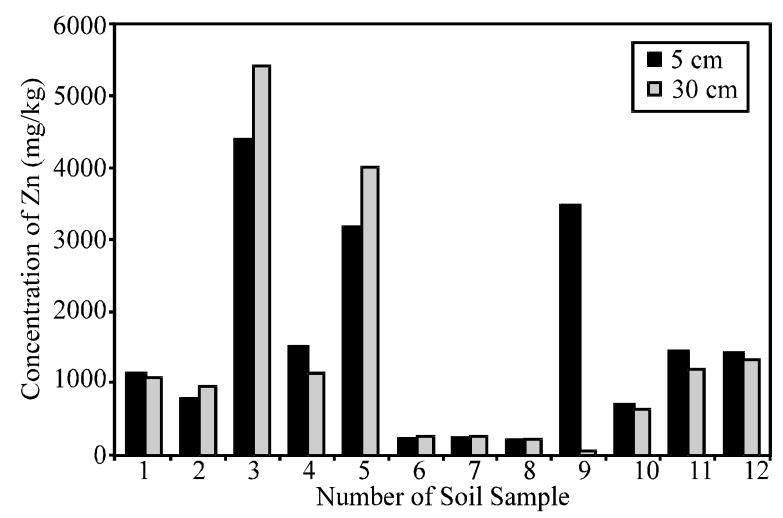

Fig. 4: Concentration of $\mathrm{Zn}$ in Soil Samples

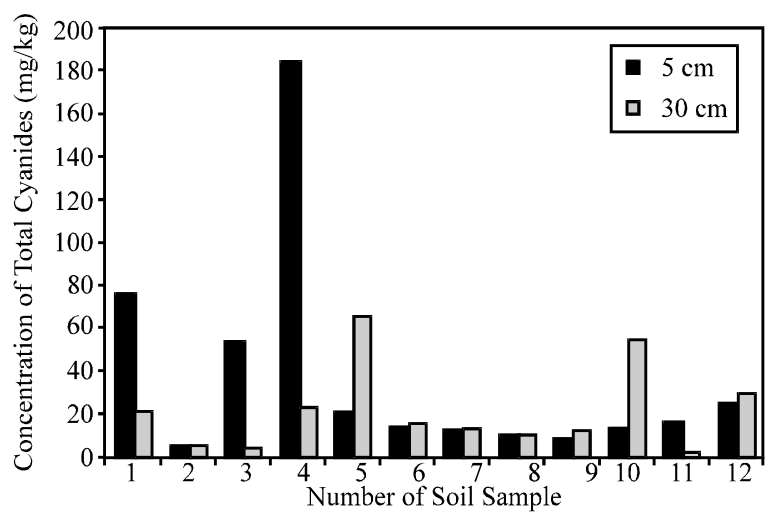

Fig. 5: Concentration of Total Cyanides in Soil Samples

the depth from which the samples were collected. The vegetation presents in certain areas may extract and accumulate the heavy metals from soil $[7,8]$. This aspect is reflected by lower concentrations of the samples collected from $30 \mathrm{~cm}$ as opposed to those collected at surface.

Very high values of the heavy metals concentration are indicated in the NE (samples 9-12) and S (samples 1-6) sides of the protection area. In exchange, the concentrations of the same metals are much lower in 
the NW side (samples 7-8). This dispersion is directly influenced by the characteristics of the area.

In the NE side (samples 9-12) of the protection area the major contribution to increased heavy metal content is attributed to the wastewaters from Transgold sedimentation pond. As it is very close to the protection area, the infiltration waters permanently maintain a very high concentration of pollutant in the area. The wastewaters coming from the others two ponds in area have a smaller role as far as the heavy metal contribution is concerned.

A significant contribution to the increased heavy metal content in the S side (samples 1-5) is attributed to the Remin sedimentation pond. As the land is slightly inclined, it collects both the infiltration waters from Transgold and Remin sedimentation ponds. The contribution of both ponds to the pollution in this area is emphasized in Figs. 2-4. The copper and zinc concentrations of samples 1-5 are higher than those of samples 9-12. The lead concentrations in the same area seem to be smaller than in the NE (Fig. 3). A possible explanation would based on the reduced solubility and mobility of the chemical combinations in which the lead is found in the sedimentation pond water compared to those of the copper and zinc.

The NW side of the protection area is located at a pretty big distance from both ponds, which explains the more reduced heavy metals (Figs. 2-4) concentrations of the soil samples (6,7 and 8).

Concentration of heavy metals in sample 7 is higher comparing to samples 6 and 8 because of location near to Remin sedimentation pond.

The total cyanide concentrations (Fig. 5) are very high, a consequence of the waters' infiltrations from the Transgold and Remin sedimentation ponds as well as the accidental spill which took place in January 2000. Samples collected in the closest areas of the sedimentation pond $(1-5,9-12)$ have highest total cyanide contents.

The accuracy of the both methods used to analyze the soil sample can be assessed based on the reproducibility of the results. For this purpose, for each type of sample the analysis of the metal content was done twice and for total cyanide content three times. Statistical parameters were calculated according to the examples in Table 2 and Table 3.

Table 4 presents the deviation of experimental results from mean value for the concentrations of heavy metals and total cyanides in each soil samples.

\section{CONCLUSION}

The values of parameters $\mathrm{s}, \mathrm{S}$ and RSD prove the accuracy of the ICP-AES and colorimetric methods employed in the analysis and recommend them for the analysis of the pollutant in soil samples.
The results of the experimental data indicate an accentuated heavy metal and cyanide pollution in the studied area caused by three sedimentation ponds.

For a more detailed analysis several area-specific aspects should be correlated: concentration of pollutant in water, air, vegetal and animal organisms and soil characteristics (texture, permeability).

\section{ACKNOWLEDGEMENTS}

We would like to acknowledge that the results presents in this paper are part of the experimental data obtained in frame of the project Investigation of the risk of cyanide in the gold leaching on health and environment in Central Asia and Central Europe (IRCYL ICA21999-10065). The research funds were provided by the European Commission and MECT-Romania. We express our thanks for the help provided by the colleagues from ICIA Cluj Napoca .

\section{REFFEERENCES}

1. Nadisan, I. and D. Chereches, 2000. Truth about pollution. Vasile Goldis University Press, Baia Mare, pp: 22.

2. Anonymous, 1999. Investigation of the risk of cyanide in the gold leaching on health and environment in Central Asia and Central Europe -IRCYL ICA2-1999-10065, Technical Annex.

3. Anonymous, 2000. Methodology for determination of the heavy metals in soil and cyanide in waters, wastewaters, soil and sediment, Study protocol of ICIA Cluj NapocaRomania.

4. Montaser, A. and D.W. Golightly, 1987. Inductively Coupled Plasmas in Analytical Atomic Spectrometry. VCH Publishers, Inc., 213: 601 .

5. Niskavaara, H., 1995. A comprehensive scheme of analysis for soils, sediments, humus and plant samples using ICP-AES. Geological Survey of Finland, 20: 167.

6. Anonymous, 1997. Romanian Order No. $756 / 1997$ of the Forests, Waters and Environment Ministry.

7. Youngman, A.L., T.L. Williams and L.S. Tien, 1998. Patterns of accumulation of heavy metals in non-wood vegetation established on zinc-lead smelter contaminated soils. Proceedings of the 1998 Conference on Hazardous Waste Research, pp: 134.

8. Hrncirova, M., 2002. Use of plants removing heavy metals. Institute of Chemical Technology, Prague. 